\title{
Review
}

\section{Pharmacogenomics and personalized medicine: a review focused on their application in the Chinese population}

\author{
Wen-ying SHU ${ }^{1,2}$, Jia-li $\mathrm{LI}^{1}$, Xue-ding WANG ${ }^{1}$, Min HUANG ${ }^{1, *}$ \\ ${ }^{1}$ Institute of Clinical Pharmacology, School of Pharmaceutical Sciences, Sun Yat-sen University, Guangzhou 510006, China; \\ ${ }^{2}$ Department of Pharmacy, Cancer Center of Guangzhou Medical University, Guangzhou 510182, China
}

The field of pharmacogenomics was initiated in the 1950 s and began to thrive after the completion of the human genome project 10 years ago. Thus far, more than 100 drug labels and clinical guidelines referring to pharmacogenomic biomarkers have been published, and several key pharmacogenomic markers for either drug safety or efficacy have been identified and subsequently adopted in clinical practice as pre-treatment genetic tests. However, a tremendous variation of genetic backgrounds exists between different ethnic groups. The application of pharmacogenomics in the Chinese population is still a long way off, since the published guidelines issued by the organizations such as US Food and Drug Administration require further confirmation in the Chinese population. This review highlights important pharmacogenomic discoveries in the Chinese population and compares the Chinese population with other nations regarding the pharmacogenomics of five most commonly used drugs, ie, tacrolimus, cyclosporine $\mathrm{A}$, warfarin, cyclophosphamide and azathioprine.

Keywords: pharmacogenomics; personalized medicine; ethnic difference; Chinese population; tacrolimus; cyclosporine A; warfarin; cyclophosphamide; azathioprine

Acta Pharmacologica Sinica (2015) 36: 535-543; doi: 10.1038/aps.2015.10; published online 20 Apr 2015

\section{Introduction}

The field of pharmacogenomics originated in the late 1950s when the term "pharmacogenetics" was first published. However, the true breakthrough in this field began 10 years ago with the completion of the human genome project. To date, many pharmacogenomic biomarkers have moved from discovery to clinical implementation. There are currently 121 Food and Drug Administration (FDA) drug labels that refer to pharmacogenomic biomarkers of drug safety or efficacy (http:/ / www.fda.gov/drugs/scienceresearch/researchareas/pharmacogenetics/ucm083378.htm). Moreover, a large number of testing guideline position papers have been published by the Clinical Pharmacogenomics Implementation Consortium $(\mathrm{CPIC})^{[1]}$. Initially, most pharmacogenomic studies focused on human cytochrome P450 enzyme (CYP) systems. There are more than 50 known human CYPs and variant alleles in these genes are being discovered continuously in various populations. Other notable enzymes with known variants and poten-

\footnotetext{
* To whom correspondence should be addressed.

E-mail huangmin@mail.sysu.edu.cn

Received 2014-11-03 Accepted 2015-01-21
}

tial clinical utility include thiopurine $S$-methyltransferase (TPMT), which is involved in thiopurine toxicity ${ }^{[2]}$. At the end of 2011 it has been estimated that, over 150000 papers reporting pharmacogenomic biomarkers have been published, with over 100 biomarkers having demonstrated clinical utility ${ }^{[3]}$. A vast number of discoveries relating to genomic variability and drug responses have been made in the last 10 years. This review aims to summarize the current state of pharmacogenomic studies and personalized medicine, with an emphasis on progress in research focusing on the Chinese population.

\section{Tacrolimus}

Transplantation followed by immunosuppressive therapy is the typical treatment for patients with end-stage organ diseases. Tacrolimus (also known as FK506) was first approved by the US FDA in 1994 and it has remarkably improved patient survival after organ transplant. However, tacrolimus treatment has many drawbacks, including a narrow therapeutic window, high inter- and intraindividual variability in pharmacokinetics/pharmacodynamics and severe adverse effects $^{[4-6]}$. Therefore, a large number of studies have been devoted to exploring personalized determination for tacroli- 
mus treatment to achieve efficacy as well as safety.

Cytochrome P450 3A4 and 3A5 (CYP3A4 and CYP3A5) are the major cytochrome P450 subtypes involved in catalyzing the phase I metabolism of tacrolimus. CYP3A4 is the major cytochrome P450 subtype in the human liver, and there is high interindividual variation in its activity. The most studied CYP3A4 mutation is CYP3A4* $1 \mathrm{~B}(-392 \mathrm{~A}>\mathrm{G})^{[7]}$. Hesselink et al reported that $\mathrm{CYP} 3 \mathrm{~A} 4 * 1 \mathrm{~B}$ allele carriers had lower tacrolimus dose-adjusted trough levels $\left(C_{0}\right)$ than those in patients with the wild-type $\left({ }^{*} 1 /{ }^{*} 1\right)$ genotype ${ }^{[8]}$, but this rare single nucleotide polymorphism (SNP) ${ }^{[9]}$ may not be the major factor in the large interindividual variance of tacrolimus pharmacokinetics. CYP3A4*1G (20230G>A) is a newly identified SNP with the highest occurrence in Asian populations, and it was reported that dose-adjusted $C_{0}$ of the patients with CYP3A $4{ }^{*} 1 /{ }^{*} 1$ was higher than the genetic groups of CYP3A $4 * 1 /{ }^{*} 1 G$ and CYP3A $4^{*} 1 G /{ }^{*} 1 G$ in Han Chinese of South China ${ }^{[10]}$. However, the definite function of CYP3A4*1G is not yet clear. A very frequent polymorphism within intron 3 of CYP3A5 (6986A>G, CYP3A $5 * 3$ allele), which causes a splicing defect that results in the absence of functional CYP3A5 protein in homozygous carriers (CYP3A5*3/*3, CYP3A5 nonexpressers), is the primary cause of its polymorphic expression ${ }^{[11,12]}$. The presence of the CYP3A5*3 allele was associated with higher dose-adjusted tacrolimus blood concentrations and lower tacrolimus requirements ${ }^{[13,14]}$, which is the only consistent conclusion among pharmacogenetic/pharmacogenomics studies of tacrolimus.

The absorption of tacrolimus is affected by P-glycoprotein (P-gp, also known as ABCB1) when administered orally. Variability of P-gp activity among individuals could influence the efficacy and toxicities of tacrolimus by changing its oral bioavailability ${ }^{[15-18]}$. In particular, the presence of P-gp in the intestine can limit tacrolimus absorption. P-gp in the liver and kidney also promotes tacrolimus efflux into the bile and urine, respectively. The P-gp efflux pump is encoded by the multidrug resistance-1 (MDR-1) gene; polymorphisms in this gene lead to polymorphic expression of P-gp in many tissues and organs (eg, liver, kidney, and small intestines). The most commonly studied ABCB1 polymorphisms include a $\mathrm{C}$ to $\mathrm{T}$ substitution at position 1236 on exon 12, a G to T/A mutation at position 2677 on exon 21 , and a $C$ to $\mathrm{T}$ substitution at position 3435 on exon $26^{[15]}$. Despite the fact that tacrolimus is a substrate of P-gp, the association between ABCB1 genotype and tacrolimus pharmacokinetics is unclear ${ }^{[19-27]}$. Even the two studies conducted by two Chinese hospitals - one in Southwest China ${ }^{[21]}$ (Chengdu, Sichuan Province) and one in East China ${ }^{[25]}$ (Hangzhou, Zhejiang Province) - presented conflicting results. This lack of consistency might be caused by the different ethnic groups included in these studies given that the ethnic situation of the patients in the two studies was not mentioned. Southwest China contains over 30 ethnic minorities, whereas the residents of East China are mainly Han Chinese. In our previous study, we found that both MDR1 genotype distribution and haplotype profiles were significantly different between the Chinese Han, Bai, Wa and Tibetan ethnic groups in Yunnan Province in Southwest China ${ }^{[28]}$. We believe that the importance of studying ABCB1 genetics as an independent factor is minimal.

Recent studies have investigated not only CYP3A4, CYP3A5 and $\mathrm{ABCB} 1$ genetic polymorphisms but also factors that could affect the activities of these three proteins. The pregnane $X$ receptor (PXR, encoded by NR1I2) is reported to be the key nuclear receptor regulating the expression of CYP3A4, CYP3A5, and ABCB1 ${ }^{[29]}$. Several PXR SNPs have been reported to be associated with the CYP3A4 or P-gp/MDR1 expression level or activity in vitro ${ }^{[29-31]}$. Differences in the distribution of PXR SNPs were found when comparing the Han Chinese of South China and Caucasian Americans ${ }^{[31]}$. PXR $-25385 \mathrm{C}>\mathrm{T}$, an SNP located in the PXR promoter and found to be correlated with CYP3A4 phenotype, was identified as a significant covariate for apparent oral clearance (CL/F) of tacrolimus by Benkali et $a l^{[32]}$, but this result could not be replicated in another study ${ }^{[33]}$. Cytochrome P450 oxidoreductase (POR) is known as the obligatory electron donor in the metabolism of drugs by CYP enzymes in humans, and the correlation between POR genetic polymorphisms and CYP-catalyzed drug metabolism has become a research hot spot. A503V (POR*28), the most studied and most common SNP in the POR coding region, has been reported to contribute more to the variation of CYP3A activity in vivo than the functional genetic variants at the CYP3A gene locus in a white population ${ }^{[34]}$. POR*28 was associated with lower tacrolimus exposure in CYP3A5 expressers in healthy male volunteers in East China (Suzhou, Jiangsu Province) ${ }^{[35]}$. However, the effect of this SNP on tacrolimus pharmacokinetics remains unclear based on the existing data $^{[10,35,36]}$.

\section{Cyclosporine A}

Cyclosporine A (also known as cyclosporin, cyclosporine or cyclosporin A) is an immunosuppressant drug that has dramatically increased graft and patient survival since it was approved in the $1970 \mathrm{~s}^{[37]}$. However, its use is limited by significant adverse side effects, in particular, acute and chronic calcineurin inhibitor nephrotoxicity ${ }^{[38,39]}$ and high variety in bioavailability, which can range from $5 \%$ to $89 \%{ }^{[40]}$. Because cyclosporine A has a narrow therapeutic index and marked interindividual pharmacokinetic variation, its usage requires monitoring the drug concentration to ensure that it is within the recommended therapeutic range. Like tacrolimus discussed above, cyclosporine A is a substrate of P-gp, and it is processed by CYP3A4 and CYP3A5 into metabolites before elimination.

Several studies have reported that renal transplant patients who were homozygous for the CYP3A5*3 genotype were exposed to a higher cyclosporine $A C_{0} /$ dose $^{[41-43]}$, whereas other studies have reported a negative correlation ${ }^{[44]}$. Notably, it was reported that CYP3A5*3 is associated with a higher cyclosporine $\mathrm{A} \mathrm{C}_{0}$ /dose in Han Chinese in North China ${ }^{[41]}$. Moreover, several studies of the CYP3A $4 * 1 \mathrm{G}$ allele in intron 10 revealed that the CYP3A4*1G genotype had lower cyclosporine A clearance than CYP3A4* $1 /{ }^{*} 1$ in Han Chinese of East China ${ }^{[45]}$. To date, an association between CYP3A4*1G and 
cyclosporine A pharmacokinetics has not been established in patients after transplantation ${ }^{[42,46,47]}$. Interestingly, two separate studies conducted by two hospitals located in different regions of China presented conflicting results, although both included Han Chinese ${ }^{[45,46]}$. One study ${ }^{[46]}$ included subjects from Northeast China (Shenyang, Liaoning Province), a region in which ethnic minorities account for approximately $5 \%$ of the total population. The other study ${ }^{[45]}$ was conducted in South China (Shanghai), where the majority of the population is Han Chinese. These conflicting results might be attributable to linkage disequilibrium (LD) between CYP3A4*1G and CYP3A5 ${ }^{*} 3$ in Asian populations ${ }^{[47-49]}$, including Han Chinese in South China ${ }^{[47]}$.

Because cyclosporine A is a substrate of P-gp, ABCB1 genetic polymorphisms might influence the amount of the drug pumped out of cells ${ }^{[50]}$. To date, researchers have focused primarily on the associations between three polymorphisms (1236 C>T in exon 12, $2677 \mathrm{G}>\mathrm{T} / \mathrm{A}$ in exon 21, and $3435 \mathrm{C}>\mathrm{T}$ in exon 26) and cyclosporine A pharmacokinetics, but the results have been inconsistent. Several studies have suggested that the non-synonymous variant $2677 \mathrm{G}>\mathrm{T} / \mathrm{A}$ and synonymous variant $3435 \mathrm{C}>\mathrm{T}$ might contribute to the differences in cyclosporine A pharmacokinetics ${ }^{[41,42]}$, but others have reported that neither polymorphism affected the cyclosporine $\mathrm{A} \mathrm{C}_{0}{ }^{[51,52]}$. Furthermore, the three SNPs were in LD with one another ${ }^{[53]}$. Carriers of the 1236TT-2677TT-3435TT haplotype had an obviously higher dose-adjusted $C_{0}$ than carriers of the other genotypes; moreover, a more obvious influence was found for the 1236TT-2677TT-3435TT haplotype compared to the individual SNP, indicating that the use of the ABCB1 haplotype is superior to SNP analysis for predicting the concentrations of cyclosporine A in Han Chinese of South China ${ }^{[54,55]}$.

Pharmacogenomic studies of cyclosporine A have focused on the effect of CYP3A and ABCB1 SNPs but yielded conflicting results ${ }^{[56]}$. Therefore, in addition to CYP3A4, CYP3A5 and $A B C B 1$ genetic polymorphisms, factors that could affect the activities of these three proteins have also been considered, such as the pregnane $X$ receptor and NF-KB. However, no association between PXR genetic polymorphisms and cyclosporine A has been found ${ }^{[5]]}$.

NF-kB, a protein complex found in almost all animal cell types, is a transcription factor that is critical for inflammatory responses. It has been reported that NF-kB competitively binds to the retinoid $X$ receptor ( $R X R$ ), thus preventing the PXR-RXR complex from binding to consensus DNA sequences in the regulatory regions of downstream genes, including CYP3A4 and ABCB1 $1^{[57]}$. The NFKB1 gene encodes the p50 subunit of NF-KB, which complexes with $\mathrm{p} 65$ to produce the major form of NF-kB, and possesses a functional common insertion/deletion (-94 ins/del ATTG) mutation in its promoter region. The del ATTG allele may result in decreased NFKB1 transcript levels and therefore decreased p50 protein production $^{[58]}$. Among non-carriers of the ABCB1 2677 TT and 3435 TT genotypes, patients with the NFKB1 6194 ATTG ins/ ins genotype had a significantly higher dose-adjusted $C_{0}$ than those with the 6194 ATTG del/del genotype ${ }^{[55]}$.

\section{Warfarin}

Since its introduction in the 1950s, warfarin has become the most commonly used oral anticoagulant for the prevention of thromboembolism in patients with deep vein thrombosis, atrial fibrillation or prosthetic heart valve replacement ${ }^{[59]}$. It is difficult to achieve the desired anticoagulation because of warfarin's narrow therapeutic window and highly variable response among individuals. The search for genetic determinants influencing warfarin response began in the 1990s. The first target genetic factor was the warfarin-metabolizing enzyme cytochrome P450 2C9 (CYP2C9) ${ }^{[60]}$. The most common variants in Caucasians are CYP2C9*2 (rs1799853), which has an Arg144Cys substitution, and CYP2C9*3 (rs1057920), which has an Ile359Thr substitution ${ }^{[61,62]}$. The mutant genes produce metabolically impaired enzymes with activities reduced by $30 \%\left(\right.$ CYP2C9*2) and $80 \%\left(\right.$ CYP2C9*3) ${ }^{[63]}$. However, CYP2C ${ }^{*} 2$ is almost absent in the Han Chinese population. Individuals who carry $\mathrm{CYP} 2 \mathrm{C}^{*} 2$ or $* 3$ require lower doses of warfarin, especially those with two copies of the $* 3$ allele ${ }^{[64,65]}$. Additional CYP2C9 variants with reduced metabolic capacity (CYP2C9*5, *6, *8, and *11) have also been identified, and these variants contribute to warfarin dose variation in African Americans ${ }^{[6,67]}$.

Except for CYP2C9, the effects of genetic polymorphisms in other metabolizing enzymes make minimal contributions to personalized medication with warfarin. For instance, polymorphisms in CYP1A ${ }^{[68]}$ and CYP3A $5^{[69]}$, enzymes that metabolize (R)-warfarin, are clinically insignificant because of the minimal effects of (R)-warfarin on anticoagulation. Genes in the vitamin $\mathrm{K}$ regeneration cycle and vitamin $\mathrm{K}$-dependent clotting factors have also been studied, including CYP2C18, CYP2C19, PROC (Protein C), ABCB1, APOE (apolipoprotein E), EPHX1 (epoxide hydrolase 1 gene), CALU (calumenin), GGCX (gamma-glutamyl carboxylase), ORM1 (orosomucoid 1), ORM2, vitamin K-dependent clotting factor II (prothrombin), VII, IX, and $X$ and $\mathrm{PXR}^{[67,69-74]}$. In addition to vitamin $\mathrm{K}$ epoxide reductase subunit 1 (VKORC1) and CYP2C9*3, CYP2C18, PROC, and EPHX1 have small but significant associations with warfarin dose in Han Chinese in Taiwan, China ${ }^{[72]}$. However, the effects of these genes were too small to have any significant clinical use.

The second major genetic determinant of warfarin processing is $\mathrm{VKORC} 1^{[75,76]}$. The most common VKORC1 variant is a noncoding variant (VKORC1 -1639 G>A, rs9923231) that lies in the promoter region of VKORC1. The $-1639 \mathrm{G}$ allele has decreased enzyme activity, so individuals who carry the $\mathrm{G}$ allele require higher warfarin doses than those with the A allele ${ }^{[7,78]}$. CYP4F2 is another genetic factor in warfarin processing. CYP4F2 contributes to vitamin K1 oxidation, and some variants could result in reduced enzyme activity ${ }^{[79]}$. An association between the CYP4F2 variant (rs2108622) and warfarin dose was subsequently confirmed in a meta-analysis involving more than 9000 participants from 30 studies $^{[80]}$. Although the association of CYP4F2 is significant, the effect size is much lower than those contributed of VKORC1 and CYP2C9 in Han Chinese in South China ${ }^{[81]}$, and its clinical use 
needs to be studied further.

\section{Cyclophosphamide}

Cyclophosphamide is a widely used immunosuppressant drug. It is a prodrug whose activity depends on bioactivation to 4-hydroxycyclophosphamide. Bioactivation of cyclophosphamide is highly variable among patients and has been attributed primarily to CYP2B6, CYP2C19, and CYP3A4 ${ }^{[82,83]}$. Additionally, cyclophosphamide and all its metabolites undergo phase II metabolism catalyzed by glutathione $S$-transferase (GST) or aldehyde dehydrogenase (ALDH). The most common variant allele of CYP2B6 in all populations contains two amino acid changes-Q172H and K262R - and is called CYP2B6*6. This haplotype occurs in approximately $15 \%$ to over $60 \%$ of individuals, depending on ethnicity ${ }^{[84]}$. Cyclophosphamide bioactivation was reported to be enhanced in the CYP2B6 ${ }^{*} 6 /{ }^{*} 6$ genotype in vitro and in vivo ${ }^{[85-87]}$. However, contradictory or negative results were presented in other studies of the association between CYP2B6 and pharmacokinetics/clinical outcome ${ }^{[88-91]}$. Notably, remarkable interindividual variety in the pharmacokinetics of cyclophosphamide and 4-hydroxycyclophosphamide had been reported in Han Chinese in South China ${ }^{[91]}$. Moreover, several studies associated other variants including CYP2B6*4, *5, *8, and *9 with lower 4-OH cyclophosphamide formation in vivo or with poor outcome ${ }^{[92-94]}$. Taken together, the in vivo and in vitro data concerning cyclophosphamide indicate that CYP2B6 polymorphism plays a role in cyclophosphamide processing, although the studies are not yet conclusive. This may be explained by different study size, design and co-medication in cancer therapy or autoimmune disease treatment. The phase II drug-metabolizing enzymes, including GST or ALDH, have also been studied in regard to personalized medication with cyclophosphamide. Several investigations of Hodgkin's lymphoma, ovarian cancer, colorectal cancer, and breast cancer have found improved survival rates associated with polymorphic forms of GSTT1, GSTM1, and GSTP1 ${ }^{\text {[95-103] }}$. The activity and genetic polymorphisms of GSTP1 were associated with clinical outcomes and toxicities of cyclophosphamide in Han Chinese (South China) with systemic lupus erythematosus ${ }^{[95]}$.

\section{Azathioprine}

Azathioprine is a cytotoxic and immunosuppressive drug that is widely used to treat autoimmune disorders, inflammatory bowel disease and acute lymphoblastic leukemia ${ }^{[104]}$. It is an inactive prodrug that has to be activated into 6-thioguanine nucleosides (6-TGN) and 6-methylmercaptopurine nucleotides (6-MMPN). Production of 6-TGN occurs through the hypoxanthine guanine phosphoribosyl-transferase (HPRT) pathway, whereas formation of 6-MMPN occurs in the TPMT pathway. Although clearly effective, azathioprine is characterized by considerable interindividual variability in clinical response, with approximately half of patients failing to achieve clinical remission and $15 \%-28 \%$ experiencing adverse effects due to overdose $^{[105,106]}$. Genetic polymorphisms of enzymes involved in thiopurine metabolism, such as TPMT, inosine triphosphate pyrophosphatase (ITPase) or xanthine oxidase (XO) could affect clinical response to thiopurines and be related to side effects ${ }^{[107]}$.

TPMT is a cytosolic methylating enzyme whose physiological role remains unclear despite extensive investigation. It is reported that a reduction in TPMT activity, caused by genetic polymorphisms results in severe and hematological toxicity in patients treated with standard doses of thiopurines ${ }^{[108,109]}$. Approximately $0.3 \%$ of individuals in a general population had low levels of TPMT activity, with approximately $10 \%$ of individuals expressing intermediate levels ${ }^{[108]}$. The TPMT gene is highly polymorphic; more than 25 variants have been identified. Four alleles (TPMT*2, *3A, *3B, and *3C) account for approximately $95 \%$ of inherited TPMT deficiency ${ }^{[109-111]}$. The wild-type allele, TPMT* 1 , encodes the fully active enzyme, and TPMT*2, TPMT*3A and TPMT*3C are the most prevalent genotypes in Caucasians, together accounting for $80 \%$ to $95 \%$ of the polymorphic alleles that lead to a significant reduction in enzyme activity due to enhanced rates of proteolysis of the mutant proteins ${ }^{[112]}$. The frequency of TPMT*3C in Chinese people has been estimated to be $2 \%-3.2 \%$ making it the major mutant allele in the Chinese population ${ }^{[113,114]}$. However, the most common low-activity allele in the Caucasian population is TPMT*3A $(\sim 5 \%)$. This allele is also found in individuals who originate from India and Pakistan, but less frequently ${ }^{[115,116]}$. The US FDA states that if a patient has clinical or laboratory evidence of severe toxicity, particularly myelosuppression, TPMT testing should be considered. Substantial dose reductions of mercaptopurine are generally required for patients homozygous for TPMT deficiency (two non-functional alleles) to avoid the development of life-threatening bone marrow suppression. Although heterozygous patients with intermediate TPMT activity may have increased mercaptopurine toxicity, this condition is variable, and the majority of patients tolerate normal doses of mercaptopurine. The CPIC guidelines describe a complete strategy for adjusting the starting dose according to TPMT activity and genotypes (Table 1) ${ }^{[110]}$.

Inosine triphosphate pyrophosphatase (ITPA) is one of several enzymes whose job is to cleanse the nucleotide pool ${ }^{[117]}$. ITPase also acts as a "cleaning" enzyme by degrading other "rogue" purine nucleotides in cells, eg, endogenous deoxyinosine triphosphate (dITP) and deoxy-xanthosine triphosphate $(\mathrm{dXTP})^{[106,118,119]}$. Five SNPs in the human ITPA gene have been identified, two of which are associated with loss of ITPase activity $(94 \mathrm{C}>\mathrm{A}$ in exon-2, and IVS2+21 A $>C$ ). These interact and affect splicing branch points resulting in the missplicing of exons 2 and 3, leading to shortening of polypeptide stretches in the enzyme ${ }^{[120]}$. The other three coding-region ITPA polymorphic sequence variants are silent mutations $(138 \mathrm{G}>\mathrm{A}, 561 \mathrm{G}>\mathrm{A} \text {, and 708G }>\mathrm{A})^{[119]}$. Approximately 1 in 15 $(6.0 \%)$ people are carriers in Caucasian populations, and these individuals have an average of approximately $22 \%$ of normal red cell ITPase activity. This allele is more common in Asian populations, with a frequency of $11 \%-15 \%^{[121]}$. It has been reported that carriers of IPTA IVS2 $+21 \mathrm{~A}>\mathrm{C}$ variants had sig- 
Table 1. Dose adjustment of azathioprine recommended by CPIC guidelines.

\begin{tabular}{|c|c|c|}
\hline Genotype of TPMT & Phenotype of TPMT & Dose adjustment \\
\hline $\begin{array}{l}\text { Carrying two or more functional alleles } \\
(* 1)\end{array}$ & High activity & $\begin{array}{l}\text { Start with normal starting dose }\left(\mathrm{eg}, 2-3 \mathrm{mg} \cdot \mathrm{kg}^{-1} \cdot \mathrm{d}^{-1}\right) \text {; allow } 2 \text { weeks to reach } \\
\text { steady state. }\end{array}$ \\
\hline $\begin{array}{l}\text { Carrying one nonfunctional allele }(* 2 \text {, } \\
\star 3 \mathrm{~A}, * 3 \mathrm{~B}, * 3 \mathrm{C} \text {, or } * 4)\end{array}$ & Intermediate activity & Start with $30 \%-70 \%$ of target dose; allow $2-4$ weeks to reach steady state. \\
\hline Carrying two nonfunctional alleles & Low or deficient activity & $\begin{array}{l}\text { Consider alternative agents or reduce daily dose by } 10 \text {-fold; allow } 4-6 \text { weeks } \\
\text { to reach steady state. Special attention is required for myelosuppression. }\end{array}$ \\
\hline
\end{tabular}

nificantly higher concentrations of 6-TGN ${ }^{[122]}$.

Xanthine oxidase $(\mathrm{XO})$ oxidizes 6-MP into 6-thioxanthine (6-TX) and subsequently into 6-thiouric acid (6-TU) ${ }^{[123]}$. This enzyme, which is predominantly expressed in the intestinal mucosa and liver, converts 6-MP to 6-TX and subsequently to the inactive metabolite 6-TU ${ }^{[124,125]}$, a principal pathway in 6-MP catabolism. However, research on XO genetic polymorphisms and azathioprine toxicities is sparse and no significant correlation has been established ${ }^{[122,126]}$.

\section{Conclusion and future directions}

Although the enthusiasm about their potential pharmacogenetic utility has prompted a number of clinical practice guidelines for pharmacogenetic results, the guidelines or conclusions specific for pharmacogenomics practice in the Chinese population are still lacking. However, most pharmacogenomics studies in Chinese subjects are conducted in individual hospitals or research centers. The results of these single hospital or center studies are often hard to reproduce or even conflict with one another, which is likely due to the differences in clinical practice in research centers or institutions. Multicenter, larger-scale and long-term studies will thus become particularly important to obtain accurate pharmacogenomic data for the Chinese population. In addition, nation-wide electronic healthcare databases through which the long-term follow-up and detailed medical records of recruited patients can be assessed by medical researchers are required for further development of personalized medicine in the Chinese population.

Another obstacle in the development of pharmacogenomics in China is the cost of genetic testing; it has not been determined whether insurance should cover the expenses. Genetic tests can suggest optimal therapy regimens, predict the likelihood of drug response/toxicities and avoid exposing patients to ineffective or overly toxic regimens. Although new technologies for genetic testing have been developing rapidly, personalized genetic testing is still too expensive for most Chinese citizens. Genomic medicine has the capacity to revolutionize clinical practice, but if insurance companies and the government are unwilling to pay for genetic testing, this important progress will be stalled. However, some have pointed out a potential disadvantage of insurance paying for the testing; the results can affect a person's health insurance coverage or increase premium. The solution first depends on privacy protection legislation to prevent genetic discrimination. Second, extensive data evaluating the economics of genetic testing is required in China.

\section{Acknowledgements}

This work was funded by the National Science and Technology Major Project through a Science and Technology grant from the Science and Technology Ministry of China (grant No 2012ZX09506001-004), the National Natural Science Foundations of China (grant No 81102515, 81320108027, 81403019, 81170215, and 81173131), the Key Laboratory Foundation of Guangdong Province (grant No 2011A060901014), the Major Scientific and Technological Project of Guangdong Province (2011A080300001 and 2012A080202013) and the Guangzhou Medical University Scientific Research Program for Young Scientists (grant № 2013A39).

\section{References}

1 Relling MV, Klein TE. CPIC: clinical pharmacogenetics implementation consortium of the pharmacogenomics research network. Clin Pharmacol Ther 2011; 89: 464-7.

2 Wang L, Pelleymounter L, Weinshilboum R, Johnson JA, Hebert $\mathrm{JM}$, Altman RB, et al. Very important pharmacogene summary: thiopurine S-methyltransferase. Pharmacogenet Genomics 2010; 20: 401-5.

3 Poste G. Bring on the biomarkers. Nature 2011; 469: 156-7.

4 Venkataramanan R, Swaminathan A, Prasad T, Jain A, Zuckerman $\mathrm{S}$, Warty $\mathrm{V}$, et al. Clinical pharmacokinetics of tacrolimus. Clin Pharmacokinet 1995; 29: 404-30.

5 Undre NA, Stevenson P, Schafer A. Pharmacokinetics of tacrolimus: clinically relevant aspects. Transplant Proc 1999; 31: 21S-24S.

6 Gu L, Jin W, Kan L, Wang X, Shan C, Fan H. A retrospective study to compare the use of tacrolimus and cyclosporine in combination with adriamycin in post-transplant liver cancer patients. Cell Biochem Biophys 2015; 71: 565-70.

7 Rebbeck TR, Jaffe JM, Walker AH, Wein AJ, Malkowicz SB. Modification of clinical presentation of prostate tumors by a novel genetic variant in CYP3A4. J Natl Cancer Inst 1998; 90: 1225-9.

8 Hesselink DA, van Schaik RH, van der Heiden IP, van der Werf M, Gregoor PJ, Lindemans J, et al. Genetic polymorphisms of the CYP3A4, CYP3A5, and MDR-1 genes and pharmacokinetics of the calcineurin inhibitors cyclosporine and tacrolimus. Clin Pharmacol 
Ther 2003; 74: 245-54.

9 Hsieh KP, Lin YY, Cheng CL, Lai ML, Lin MS, Siest JP, et al. Novel mutations of CYP3A4 in Chinese. Drug Metab Dispos 2001; 29: 268-73.

10 Li CJ, Li L, Lin L, Jiang HX, Zhong ZY, Li WM, et al. Impact of the CYP3A5, CYP3A4, COMT, IL-10, and POR genetic polymorphisms on tacrolimus metabolism in Chinese renal transplant recipients. PLoS One 2014; 9: e86206.

11 Hustert E, Haberl M, Burk O, Wolbold R, He YQ, Klein K, et al. The genetic determinants of the CYP3A5 polymorphism. Pharmacogenetics 2001; 11: 773-9.

12 Kuehl P, Zhang J, Lin Y, Lamba J, Assem M, Schuetz J, et al. Sequence diversity in CYP3A promoters and characterization of the genetic basis of polymorphic CYP3A5 expression. Nat Genet 2001; 27: 383-91.

13 Ware N, MacPhee IA. Current progress in pharmacogenetics and individualized immunosuppressive drug dosing in organ transplantation. Curr Opin Mol Ther 2010; 12: 270-83.

14 Macphee IA, Fredericks S, Mohamed M, Moreton M, Carter ND, Johnston A, et al. Tacrolimus pharmacogenetics: the CYP3A5*1 allele predicts low dose-normalized tacrolimus blood concentrations in whites and South Asians. Transplantation 2005; 79: 499-502.

15 Anglicheau D, Verstuyft C, Laurent-Puig P, Becquemont L, Schlageter $\mathrm{MH}$, Cassinat B, et al. Association of the multidrug resistance-1 gene single-nucleotide polymorphisms with the tacrolimus dose requirements in renal transplant recipients. J Am Soc Nephrol 2003; 14 : 1889-96.

16 Li Y, Hu X, Cai B, Chen J, Bai Y, Tang J, et al. Meta-analysis of the effect of MDR1 C3435 polymorphism on tacrolimus pharmacokinetics in renal transplant recipients. Transpl Immunol 2012; 27 : 12-8.

17 Akbas SH, Bilgen T, Keser I, Tuncer M, Yucetin L, Tosun O, et al. The effect of MDR1 (ABCB1) polymorphism on the pharmacokinetic of tacrolimus in Turkish renal transplant recipients. Transplant Proc 2006; 38: 1290-2.

18 Singh R, Srivastava A, Kapoor R, Mittal RD. Do drug transporter (ABCB1) SNPs influence cyclosporine and tacrolimus dose requirements and renal allograft outcome in the posttransplantation period? J Clin Pharmacol 2011; 51: 603-15.

19 Goto M, Masuda S, Kiuchi T, Ogura Y, Oike F, Okuda M, et al. CYP3A5*1-carrying graft liver reduces the concentration/oral dose ratio of tacrolimus in recipients of living-donor liver transplantation. Pharmacogenetics 2004; 14: 471-8.

20 Herrero MJ, Sanchez-Plumed J, Galiana M, Bea S, Marques MR, Alino SF. Influence of pharmacogenetic polymorphisms in routine immunosuppression therapy after renal transplantation. Transplant Proc 2010; 42: 3134-6.

21 Wei-lin W, Jing J, Shu-sen Z, Li-hua W, Ting-bo L, Song-feng Y, et al. Tacrolimus dose requirement in relation to donor and recipient ABCB1 and CYP3A5 gene polymorphisms in Chinese liver transplant patients. Liver Transpl 2006; 12: 775-80.

22 Lopez-Montenegro Soria MA, Kanter Berga J, Beltran Catalan S, Milara Paya J, Pallardo Mateu LM, Jimenez Torres NV. Genetic polymorphisms and individualized tacrolimus dosing. Transplant Proc 2010; 42: 3031-3.

23 Provenzani A, Notarbartolo M, Labbozzetta M, Poma P, Biondi F, Sanguedolce $R$, et al. The effect of CYP3A5 and ABCB1 single nucleotide polymorphisms on tacrolimus dose requirements in Caucasian liver transplant patients. Ann Transplant 2009; 14: 2331.

$24 \mathrm{Cho} \mathrm{JH}$, Yoon YD, Park JY, Song EJ, Choi JY, Yoon SH, et al. Impact of cytochrome P450 3A and ATP-binding cassette subfamily B member 1 polymorphisms on tacrolimus dose-adjusted trough concentrations among Korean renal transplant recipients. Transplant Proc 2012; 44: 109-14.

25 Shi Y, Li Y, Tang J, Zhang J, Zou Y, Cai B, et al. Influence of CYP3A4, CYP3A5 and MDR-1 polymorphisms on tacrolimus pharmacokinetics and early renal dysfunction in liver transplant recipients. Gene 2013; 512: 226-31.

26 Jun KR, Lee W, Jang MS, Chun S, Song GW, Park KT, et al. Tacrolimus concentrations in relation to CYP3A and ABCB1 polymorphisms among solid organ transplant recipients in Korea. Transplantation 2009; 87: 1225-31.

27 Provenzani A, Notarbartolo M, Labbozzetta M, Poma P, Vizzini G, Salis $P$, et al. Influence of CYP3A5 and ABCB1 gene polymorphisms and other factors on tacrolimus dosing in Caucasian liver and kidney transplant patients. Int J Mol Med 2011; 28: 1093-102.

28 Lai Y, Huang M, Li H, Wang XD, Li JL. Distinct genotype distribution and haplotype profiles in MDR1 gene among Chinese Han, Bai, Wa, and Tibetan ethnic groups. Pharmazie 2012; 67: 938-41.

29 Zhang J, KuehI P, Green ED, Touchman JW, Watkins PB, Daly A, et al. The human pregnane $X$ receptor: genomic structure and identification and functional characterization of natural allelic variants. Pharmacogenetics 2001; 11: 555-72.

30 Lamba J, Lamba V, Strom S, Venkataramanan R, Schuetz E. Novel single nucleotide polymorphisms in the promoter and intron 1 of human pregnane $\mathrm{X}$ receptor/NR1I2 and their association with CYP3A4 expression. Drug Metab Dispos 2008; 36: 169-81.

31 Wang XD, Deng XY, Chen J, Li JL, Chen X, Zhao LZ, et al. Single nucleotide polymorphisms of the pregnane $x$ receptor gene in Han Chinese and a comparison with other ethnic populations. Pharmacology 2008; 81: 350-4.

32 Benkali K, Premaud A, Picard N, Rerolle JP, Toupance O, Hoizey G, et al. Tacrolimus population pharmacokinetic-pharmacogenetic analysis and Bayesian estimation in renal transplant recipients. Clin Pharmacokinet 2009; 48: 805-16.

33 Press RR, Ploeger BA, den Hartigh J, van der Straaten T, van Pelt J, Danhof $\mathrm{M}$, et al. Explaining variability in tacrolimus pharmacokinetics to optimize early exposure in adult kidney transplant recipients. Ther Drug Monit 2009; 31: 187-97.

34 Oneda B, Crettol S, Jaquenoud Sirot E, Bochud M, Ansermot N, Eap CB. The P450 oxidoreductase genotype is associated with CYP3A activity in vivo as measured by the midazolam phenotyping test. Pharmacogenet Genomics 2009; 19: 877-83.

35 Zhang JJ, Zhang H, Ding XL, Ma S, Miao LY. Effect of the P450 oxidoreductase 28 polymorphism on the pharmacokinetics of tacrolimus in Chinese healthy male volunteers. Eur J Clin Pharmacol 2013; 69: 807-12.

36 Kuypers DR, de Loor $\mathrm{H}$, Naesens M, Coopmans T, de Jonge $\mathrm{H}$. Combined effects of CYP3A5*1, POR $* 28$, and CYP3A $4 * 22$ single nucleotide polymorphisms on early concentration-controlled tacrolimus exposure in de-novo renal recipients. Pharmacogenet Genomics 2014; 24: 597-606.

37 Calne RY, White DJ, Thiru S, Evans DB, McMaster P, Dunn DC, et al. Cyclosporin $A$ in patients receiving renal allografts from cadaver donors. Lancet 1978; 2: 1323-7.

38 Klintmalm GB, Iwatsuki S, Starzl TE. Nephrotoxicity of cyclosporin A in liver and kidney transplant patients. Lancet 1981; 1: 470-1.

39 Myers BD, Ross J, Newton L, Luetscher J, Perlroth M. Cyclosporineassociated chronic nephropathy. N Engl J Med 1984; 311: 699-705.

40 Ptachcinski RJ, Venkataramanan R, Burckart GJ. Clinical pharmacokinetics of cyclosporin. Clin Pharmacokinet 1986; 11: 107-32. 
41 Hu YF, Qiu W, Liu ZQ, Zhu L, Liu ZQ, Tu JH, et al. Effects of genetic polymorphisms of CYP3A4, CYP3A5 and MDR1 on cyclosporine pharmacokinetics after renal transplantation. Clin Exp Pharmacol Physiol 2006; 33: 1093-8.

42 Qiu XY, Jiao Z, Zhang M, Zhong LJ, Liang HQ, Ma CL, et al. Association of MDR1, CYP3A4*18B, and CYP3A5*3 polymorphisms with cyclosporine pharmacokinetics in Chinese renal transplant recipients. Eur J Clin Pharmacol 2008; 64: 1069-84.

43 Turolo S, Tirelli AS, Ferraresso M, Ghio L, Belingheri M, Groppali E, et al. Frequencies and roles of CYP3A5, CYP3A4 and ABCB1 single nucleotide polymorphisms in Italian teenagers after kidney transplantation. Pharmacol Rep 2010; 62: 1159-69.

44 Bouamar R, Hesselink DA, van Schaik RH, Weimar W, Macphee IA, de Fijter JW, et al. Polymorphisms in CYP3A5, CYP3A4, and ABCB1 are not associated with cyclosporine pharmacokinetics nor with cyclosporine clinical end points after renal transplantation. Ther Drug Monit 2011; 33: 178-84.

45 Shi XJ, Geng F, Jiao Z, Cui XY, Qiu XY, Zhong MK. Association of $A B C B 1, C Y P 3 A 4 * 18 B$ and CYP3A5*3 genotypes with the pharmacokinetics of tacrolimus in healthy Chinese subjects: a population pharmacokinetic analysis. J Clin Pharm Ther 2011; 36: 614-24.

46 Qiu F, He XJ, Sun YX, Li-Ling J, Zhao LM. Influence of ABCB1, CYP3A4*18B and CYP3A5*3 polymorphisms on cyclosporine $A$ pharmacokinetics in bone marrow transplant recipients. Pharmacol Rep 2011; 63: 815-25.

47 Meng XG, Guo CX, Feng GQ, Zhao YC, Zhou BT, Han JL, et al. Association of CYP3A polymorphisms with the pharmacokinetics of cyclosporine A in early post-renal transplant recipients in China. Acta Pharmacol Sin 2012; 33: 1563-70.

48 Fukushima-Uesaka H, Saito Y, Watanabe H, Shiseki K, Saeki M, Nakamura T, et al. Haplotypes of CYP3A4 and their close linkage with CYP3A5 haplotypes in a Japanese population. Hum Mutat 2004; 23: 100.

49 Miura M, Satoh S, Kagaya H, Saito M, Numakura K, Tsuchiya N, et al. Impact of the CYP3A4*1G polymorphism and its combination with CYP3A5 genotypes on tacrolimus pharmacokinetics in renal transplant patients. Pharmacogenomics 2011; 12: 977-84.

50 Haufroid V. Genetic polymorphisms of ATP-binding cassette transporters $A B C B 1$ and $A B C C 2$ and their impact on drug disposition. Curr Drug Targets 2011; 12: 631-46.

51 Santoro A, Felipe CR, Tedesco-Silva H, Medina-Pestana JO, Struchiner CJ, Ojopi EB, et al. Pharmacogenetics of calcineurin inhibitors in Brazilian renal transplant patients. Pharmacogenomics 2011; 12: 1293-303.

52 Azarpira N, Aghdaie MH, Behzad-Behbahanie A, Geramizadeh B, Behzadi S, Malekhoseinie SA, et al. Association between cyclosporine concentration and genetic polymorphisms of CYP3A5 and MDR1 during the early stage after renal transplantation. Exp Clin Transplant 2006; 4: 416-9.

53 Kroetz DL, Pauli-Magnus C, Hodges LM, Huang CC, Kawamoto M, Johns SJ, et al. Sequence diversity and haplotype structure in the human ABCB1 (MDR1, multidrug resistance transporter) gene. Pharmacogenetics 2003; 13: 481-94.

54 Wang Y, Wang C, Li J, Wang X, Zhu G, Chen X, et al. Effect of genetic polymorphisms of CYP3A5 and MDR1 on cyclosporine concentration during the early stage after renal transplantation in Chinese patients co-treated with diltiazem. Eur J Clin Pharmacol 2009; 65: 239-47.

55 Zhang Y, Li JL, Fu Q, Wang XD, Liu LS, Wang CX, et al. Associations of ABCB1, NFKB1, CYP3A, and NR1/2 polymorphisms with cyclosporine trough concentrations in Chinese renal transplant recipients. Acta Pharmacol Sin 2013; 34: 555-60.
56 Staatz CE, Goodman LK, Tett SE. Effect of CYP3A and ABCB1 single nucleotide polymorphisms on the pharmacokinetics and pharmacodynamics of calcineurin inhibitors: Part I. Clin Pharmacokinet 2010; 49: 141-75.

$57 \mathrm{Gu}$ X. Role of NF-kB in regulation of PXR-mediated gene expression: a mechanism for the suppression of cytochrome P-450 3A4 by proinflammatory agents. J Biol Chem 2006; 281: 17882-89.

58 Karban AS, Okazaki T, Panhuysen Cl, Gallegos T, Potter JJ, BaileyWilson JE, et al. Functional annotation of a novel NFKB1 promoter polymorphism that increases risk for ulcerative colitis. Hum Mol Genet 2004; 13: 35-45.

59 Hirsh J, Dalen J, Anderson DR, Poller L, Bussey H, Ansell J, et al. Oral anticoagulants: mechanism of action, clinical effectiveness, and optimal therapeutic range. Chest 2001; 119: 8S-21S.

60 Rettie AE, Korzekwa KR, Kunze KL, Lawrence RF, Eddy AC, Aoyama $\mathrm{T}$, et al. Hydroxylation of warfarin by human CDNA-expressed cytochrome P-450: a role for P-4502C9 in the etiology of S-warfarin-drug interactions. Chem Res Toxicol 1992; 5: 54-9.

61 Takahashi H, Echizen H. Pharmacogenetics of CYP2C9 and interindividual variability in anticoagulant response to warfarin. Pharmacogenomics J 2003; 3: 202-14.

62 Sullivan-Klose TH, Ghanayem BI, Bell DA, Zhang ZY, Kaminsky LS, Shenfield GM, et al. The role of the CYP2C9-Leu359 allelic variant in the tolbutamide polymorphism. Pharmacogenetics 1996; 6: 341-9.

63 Furuya H, Fernandez-Salguero P, Gregory W, Taber H, Steward A, Gonzalez FJ, et al. Genetic polymorphism of CYP2C9 and its effect on warfarin maintenance dose requirement in patients undergoing anticoagulation therapy. Pharmacogenetics 1995; 5: 389-92.

64 Aithal GP, Day CP, Kesteven PJ, Daly AK. Association of polymorphisms in the cytochrome P450 CYP2C9 with warfarin dose requirement and risk of bleeding complications. Lancet 1999; 353: 717-9.

65 Lindh JD, Holm L, Andersson ML, Rane A. Influence of CYP2C9 genotype on warfarin dose requirements--a systematic review and meta-analysis. Eur J Clin Pharmacol 2009; 65: 365-75.

66 Scott SA, Jaremko M, Lubitz SA, Kornreich R, Halperin JL, Desnick RJ. CYP2C9*8 is prevalent among African-Americans: implications for pharmacogenetic dosing. Pharmacogenomics 2009; 10: 1243-55.

67 Cavallari LH, Langaee TY, Momary KM, Shapiro NL, Nutescu EA, Coty WA, et al. Genetic and clinical predictors of warfarin dose requirements in African Americans. Clin Pharmacol Ther 2010; 87: 459-64.

68 Kaminsky LS, Zhang ZY. Human P450 metabolism of warfarin. Pharmacol Ther 1997; 73: 67-74.

69 Wadelius M, Sorlin K, Wallerman O, Karlsson J, Yue QY, Magnusson $\mathrm{PK}$, et al. Warfarin sensitivity related to CYP2C9, CYP3A5, ABCB1 (MDR1) and other factors. Pharmacogenomics J 2004; 4: 40-8.

70 Otagiri M, Maruyama T, Imai T, Suenaga A, Imamura Y. A comparative study of the interaction of warfarin with human alpha 1-acid glycoprotein and human albumin. J Pharm Pharmacol 1987; 39: 416-20.

71 Wadelius M, Chen LY, Downes K, Ghori J, Hunt S, Eriksson N, et al. Common VKORC1 and GGCX polymorphisms associated with warfarin dose. Pharmacogenomics J 2005; 5: 262-70.

72 Lee MT, Chen CH, Chou CH, Lu LS, Chuang HP, Chen YT, et al. Genetic determinants of warfarin dosing in the Han-Chinese population. Pharmacogenomics 2009; 10: 1905-13.

73 Kimura R, Miyashita K, Kokubo Y, Akaiwa Y, Otsubo R, Nagatsuka K, et al. Genotypes of vitamin $\mathrm{K}$ epoxide reductase, gamma-glutamyl carboxylase, and cytochrome P450 2C9 as determinants of daily warfarin dose in Japanese patients. Thromb Res 2007; 120: 181-6.

74 Suriapranata IM, Tjong WY, Wang T, Utama A, Raharjo SB, Yuniadi Y, et al. Genetic factors associated with patient-specific warfarin dose 
in ethnic Indonesians. BMC Med Genet 2011; 12: 80.

75 Li T, Chang CY, Jin DY, Lin PJ, Khvorova A, Stafford DW. Identification of the gene for vitamin $\mathrm{K}$ epoxide reductase. Nature 2004; 427 : 541-4.

76 Rost S, Fregin A, Ivaskevicius V, Conzelmann E, Hortnagel K, Pelz HJ, et al. Mutations in VKORC1 cause warfarin resistance and multiple coagulation factor deficiency type 2 . Nature 2004; 427: 537-41.

77 International Warfarin Pharmacogenetics C, Klein TE, Altman RB, Eriksson N, Gage BF, Kimmel SE, et al. Estimation of the warfarin dose with clinical and pharmacogenetic data. N Engl J Med 2009; 360: 753-64.

78 Limdi NA, Wadelius M, Cavallari L, Eriksson N, Crawford DC, Lee MT, et al. Warfarin pharmacogenetics: a single VKORC1 polymorphism is predictive of dose across 3 racial groups. Blood 2010; 115: $3827-$ 34.

79 McDonald MG, Rieder MJ, Nakano M, Hsia CK, Rettie AE. CYP4F2 is a vitamin $\mathrm{K} 1$ oxidase: An explanation for altered warfarin dose in carriers of the V433M variant. Mol Pharmacol 2009; 75: 1337-46.

80 Danese E, Montagnana M, Johnson JA, Rettie AE, Zambon CF, Lubitz SA, et al. Impact of the CYP4F2 p.V433M polymorphism on coumarin dose requirement: systematic review and meta-analysis. Clin Pharmacol Ther 2012; 92: 746-56.

81 Cen $\mathrm{HJ}$, Zeng WT, Leng XY, Huang M, Chen X, Li JL, et al. CYP4F2 rs2108622: a minor significant genetic factor of warfarin dose in Han Chinese patients with mechanical heart valve replacement. $\mathrm{Br} J$ Clin Pharmacol 2010; 70: 234-40.

82 Chang TK, Weber GF, Crespi CL, Waxman DJ. Differential activation of cyclophosphamide and ifosphamide by cytochromes P-450 2B and 3A in human liver microsomes. Cancer Res 1993; 53: 5629-37.

83 Raccor BS, Claessens AJ, Dinh JC, Park JR, Hawkins DS, Thomas SS, et al. Potential contribution of cytochrome P450 2B6 to hepatic 4-hydroxycyclophosphamide formation in vitro and in vivo. Drug Metab Dispos 2012; 40: 54-63.

84 Guan S, Huang M, Chan E, Chen X, Duan W, Zhou SF. Genetic polymorphisms of cytochrome P450 2B6 gene in Han Chinese. Eur J Pharm Sci 2006; 29: 14-21.

85 Xie HJ, Yasar U, Lundgren S, Griskevicius L, Terelius Y, Hassan M, et al. Role of polymorphic human CYP2B6 in cyclophosphamide bioactivation. Pharmacogenomics J 2003; 3: 53-61.

86 Xie H, Griskevicius L, Stahle L, Hassan Z, Yasar U, Rane A, et al. Pharmacogenetics of cyclophosphamide in patients with hematological malignancies. Eur J Pharm Sci 2006; 27: 54-61.

87 Nakajima M, Komagata S, Fujiki Y, Kanada Y, Ebi H, Itoh K, et al. Genetic polymorphisms of CYP2B6 affect the pharmacokinetics/ pharmacodynamics of cyclophosphamide in Japanese cancer patients. Pharmacogenet Genomics 2007; 17: 431-45.

88 Singh G, Saxena N, Aggarwal A, Misra R. Cytochrome P450 polymorphism as a predictor of ovarian toxicity to pulse cyclophosphamide in systemic lupus erythematosus. J Rheumatol 2007; 34: 731-3.

89 Ekhart C, Doodeman VD, Rodenhuis S, Smits PH, Beijnen JH, Huitema AD. Influence of polymorphisms of drug metabolizing enzymes (CYP2B6, CYP2C9, CYP2C19, CYP3A4, CYP3A5, GSTA1, GSTP1, ALDH1A1 and ALDH3A1) on the pharmacokinetics of cyclophosphamide and 4-hydroxycyclophosphamide. Pharmacogenet Genomics 2008; 18: 515-23.

90 Melanson SE, Stevenson K, Kim H, Antin JH, Court MH, Ho VT, et al. Allelic variations in CYP2B6 and CYP2C19 and survival of patients receiving cyclophosphamide prior to myeloablative hematopoietic stem cell transplantation. Am J Hematol 2010; 85: 967-71.

91 Shu W, Wang X, Yang X, Liang L, Li J, Chen Z, et al. Simultaneous determination of cyclophosphamide and 4-hydroxycyclophosphamide in human plasma by high-performance liquid chromatography coupled with electrospray ionization tandem mass spectrometryapplication to Chinese systemic lupus erythematosus patients. Clin Chem Lab Med 2011; 49: 2029-37.

92 Takada K, Arefayene M, Desta Z, Yarboro CH, Boumpas DT, Balow JE, et al. Cytochrome P450 pharmacogenetics as a predictor of toxicity and clinical response to pulse cyclophosphamide in lupus nephritis. Arthritis Rheum 2004; 50: 2202-10.

93 Bray J, Sludden J, Griffin MJ, Cole M, Verrill M, Jamieson D, et al. Influence of pharmacogenetics on response and toxicity in breast cancer patients treated with doxorubicin and cyclophosphamide. $\mathrm{Br}$ J Cancer 2010; 102: 1003-9.

94 Joy MS, La M, Wang J, Bridges AS, Hu Y, Hogan SL, et al. Cyclophosphamide and 4-hydroxycyclophosphamide pharmacokinetics in patients with glomerulonephritis secondary to lupus and small vessel vasculitis. Br J Clin Pharmacol 2012; 74: 445-55.

95 Zhong S, Huang M, Yang X, Liang L, Wang Y, Romkes M, et al. Relationship of glutathione $S$-transferase genotypes with side-effects of pulsed cyclophosphamide therapy in patients with systemic lupus erythematosus. Br J Clin Pharmacol 2006; 62: 457-72.

96 Khedhaier A, Remadi S, Corbex M, Ahmed SB, Bouaouina N, Mestiri S, et al. Glutathione S-transferases (GSTT1 and GSTM1) gene deletions in Tunisians: susceptibility and prognostic implications in breast carcinoma. Br J Cancer 2003; 89: 1502-7.

97 Huang E, West M, Nevins JR. Gene expression profiling for prediction of clinical characteristics of breast cancer. Recent Prog Horm Res 2003; 58: 55-73.

98 Hohaus S, Di Ruscio A, Di Febo A, Massini G, D’Alo F, Guidi F, et al. Glutathione S-transferase P1 genotype and prognosis in Hodgkin's lymphoma. Clin Cancer Res 2005; 11: 2175-9.

99 Holley SL, Rajagopal R, Hoban PR, Deakin M, Fawole AS, Elder JB, et al. Polymorphisms in the glutathione S-transferase mu cluster are associated with tumour progression and patient outcome in colorectal cancer. Int J Oncol 2006; 28: 231-6.

100 Kweekel DM, Koopman M, Antonini NF, Van der Straaten T, Nortier JW, Gelderblom H, et al. GSTP1 lle105Val polymorphism correlates with progression-free survival in MCRC patients treated with or without irinotecan: a study of the Dutch Colorectal Cancer Group. $\mathrm{Br}$ J Cancer 2008; 99: 1316-21.

101 Kolwijck E, Zusterzeel PL, Roelofs HM, Hendriks JC, Peters WH, Massuger LF. GSTP1-1 in ovarian cyst fluid and disease outcome of patients with ovarian cancer. Cancer Epidemiol Biomarkers Prev 2009; 18: 2176-81.

102 Khrunin AV, Moisseev A, Gorbunova V, Limborska S. Genetic polymorphisms and the efficacy and toxicity of cisplatin-based chemotherapy in ovarian cancer patients. Pharmacogenomics $J$ 2010; 10: 54-61.

103 Oliveira AL, Oliveira Rodrigues FF, Dos Santos RE, Rozenowicz RL, Barbosa de Melo M. GSTT1, GSTM1, and GSTP1 polymorphisms as a prognostic factor in women with breast cancer. Genet Mol Res 2014; 13: 2521-30.

104 Chouchana L, Narjoz C, Beaune P, Loriot MA, Roblin X. Review article: the benefits of pharmacogenetics for improving thiopurine therapy in inflammatory bowel disease. Aliment Pharmacol Ther 2012; 35: 15-36.

105 Fraser AG, Orchard TR, Jewell DP. The efficacy of azathioprine for the treatment of inflammatory bowel disease: a 30 year review. Gut 2002; 50: 485-9.

106 Marinaki AM, Ansari A, Duley JA, Arenas M, Sumi S, Lewis CM, et al. Adverse drug reactions to azathioprine therapy are associated 
with polymorphism in the gene encoding inosine triphosphate pyrophosphatase (ITPase). Pharmacogenetics 2004; 14: 181-7.

107 Wroblova K, Kolorz M, Batovsky M, Zboril V, Suchankova J, Bartos M, et al. Gene polymorphisms involved in manifestation of leucopenia, digestive intolerance, and pancreatitis in azathioprine-treated patients. Dig Dis Sci 2012; 57: 2394-401.

108 Weinshilboum RM, Sladek SL. Mercaptopurine pharmacogenetics: monogenic inheritance of erythrocyte thiopurine methyltransferase activity. Am J Hum Genet 1980; 32: 651-62.

109 Salavaggione OE, Wang L, Wiepert M, Yee VC, Weinshilboum RM. Thiopurine S-methyltransferase pharmacogenetics: variant allele functional and comparative genomics. Pharmacogenet Genomics 2005; 15: 801-15.

110 Relling MV, Gardner EE, Sandborn WJ, Schmiegelow K, Pui CH, Yee $\mathrm{SW}$, et al. Clinical Pharmacogenetics Implementation Consortium guidelines for thiopurine methyltransferase genotype and thiopurine dosing. Clin Pharmacol Ther 2011; 89: 387-91.

111 Szumlanski C, Otterness D, Her C, Lee D, Brandriff B, Kelsell D, et al. Thiopurine methyltransferase pharmacogenetics: human gene cloning and characterization of a common polymorphism. DNA Cell Biol 1996; 15: 17-30.

112 Yates CR, Krynetski EY, Loennechen T, Fessing MY, Tai HL, Pui CH, et al. Molecular diagnosis of thiopurine S-methyltransferase deficiency: genetic basis for azathioprine and mercaptopurine intolerance. Ann Intern Med 1997; 126: 608-14.

113 Collie-Duguid ES, Pritchard SC, Powrie RH, Sludden J, Collier DA, Li T, et al. The frequency and distribution of thiopurine methyltransferase alleles in Caucasian and Asian populations. Pharmacogenetics 1999; 9: 37-42.

114 Kham SK, Tan PL, Tay AH, Heng CK, Yeoh AE, Quah TC. Thiopurine methyltransferase polymorphisms in a multiracial asian population and children with acute lymphoblastic leukemia. J Pediatr Hematol Oncol 2002; 24: 353-9.

115 Schutz E, Gummert J, Mohr F, Oellerich M. Azathioprine-induced myelosuppression in thiopurine methyltransferase deficient heart transplant recipient. Lancet 1993; 341: 436.

116 Krynetski EY, Evans WE. Pharmacogenetics as a molecular basis for individualized drug therapy: the thiopurine S-methyltransferase paradigm. Pharm Res 1999; 16: 342-9.

117 Bierau J, Lindhout M, Bakker JA. Pharmacogenetic significance of inosine triphosphatase. Pharmacogenomics 2007; 8: 1221-8.

118 Lin S, McLennan AG, Ying K, Wang Z, Gu S, Jin H, et al. Cloning, expression, and characterization of a human inosine triphosphate pyrophosphatase encoded by the itpa gene. J Biol Chem 2001; 276 : 18695-701.

119 Sumi S, Marinaki AM, Arenas M, Fairbanks L, Shobowale-Bakre M, Rees DC, et al. Genetic basis of inosine triphosphate pyrophosphohydrolase deficiency. Hum Genet 2002; 111: 360-7.

120 Arenas M, Duley J, Sumi S, Sanderson J, Marinaki A. The ITPA c.94C>A and g.IVS2 $+21 A>C$ sequence variants contribute to missplicing of the ITPA gene. Biochim Biophys Acta 2007; 1772: 96-102.

121 Marsh S, King CR, Ahluwalia R, McLeod HL. Distribution of ITPA P32T alleles in multiple world populations. J Hum Genet 2004; 49: 579-81.

122 Hawwa AF, Millership JS, Collier PS, Vandenbroeck K, McCarthy A, Dempsey $S$, et al. Pharmacogenomic studies of the anticancer and immunosuppressive thiopurines mercaptopurine and azathioprine. Br J Clin Pharmacol 2008; 66: 517-28.

123 Bostrom B, Erdmann G. Cellular pharmacology of 6-mercaptopurine in acute lymphoblastic leukemia. Am J Pediatr Hematol Oncol 1993; 15: 80-6.

124 Zimm S, Collins JM, Riccardi R, O'Neill D, Narang PK, Chabner B, et al. Variable bioavailability of oral mercaptopurine. Is maintenance chemotherapy in acute lymphoblastic leukemia being optimally delivered? N Engl J Med 1983; 308: 1005-9.

125 Krynetski EY, Krynetskaia NF, Yanishevski Y, Evans WE. Methylation of mercaptopurine, thioguanine, and their nucleotide metabolites by heterologously expressed human thiopurine S-methyltransferase. Mol Pharmacol 1995; 47: 1141-7.

126 Jharap B, de Boer N, Vos R, Smid K, Zwiers A, Peters G, et al. Biotransformation of 6-thioguanine in inflammatory bowel disease patients: a comparison of oral and intravenous administration of 6-thioguanine. Br J Pharmacol 2011; 163: 722-31. 